\title{
Intra-arterial chemotherapy for retinoblastoma: a practical review
}

\author{
Jorge Balderrama ${ }^{1}$, Carlos A. Leal-Leal ${ }^{2}$, Hernando Alvis-Miranda $^{3}$, \\ Angel Lee ${ }^{4}$, Marco Zenteno ${ }^{1}$, Luis Rafael Moscote-Salazar ${ }^{1}$ \\ ${ }^{1}$ Instituto Nacional de Neurología y Neurocirugía \\ ${ }^{2}$ Instituto Nacional de Pediatria Hospital, Idi-Araba, Lagos State. Nigeria \\ ${ }^{3}$ Hospital Angeles del Pedregal
}

\begin{abstract}
The use of chemotherapy for retinoblastoma constitutes a promising treatment strategy. Retinoblastoma is the most common eye cancer in the childhood.. Treatment depends on the laterality, intraocular location and tumor extension. Radiation therapy became an important element in the management of this type of injury risk of extraocular secondary tumor development. Eye salvage is mandatory when vision preserved. The current neuroendovascular techniques constitute a therapeutic tool for these tumors. We present a practical review of current concepts in the management of these tumors.
\end{abstract}

Key words: chemosurgery, retinoblastoma, neurointerventional

\section{Introduction}

Retinoblastoma (RTB) is a tumor that surge from the retinal neuroepithelium, and can differentiate into almost any type of outer or inner retinal cell, including photoreceptors (1). RTB is brought about by biallelic inactivation of the human retinoblastoma susceptibility gene, RB1
(GenBank accession number L11910), located on chromosome $13 \mathrm{q} 14$ that codes for the RB protein (2). RTB protein $(\mathrm{Rb})$ regulates cell cycle progression and suppresses tumorigenesis through the control of E2F transcription factor function, which in turn represents the link between the $\mathrm{Rb}$ pathway and the induction of p53dependent apoptosis (3-5). RTB arises due to two genetic events involving both the alleles of RB1 and occurs in two forms, the hereditary and non-hereditary. Mutation of both the alleles of RB1 is required for tumor initiation (2).

RTB can be unilateral or bilateral with sporadic or familial hereditary patterns. Patients with unilateral retinoblastoma generally carry a somatic mutation in the $\mathrm{Rb}$ that is present only in the tumor without a similar mutation in other cells (6). However, almost $10 \%$ to $15 \%$ of these patients manifest a germinal mutation in all cells of the body, despite the fact that they have unilateral RTB (6). Tables 1 and 2, show two classification systems for RTB. The aim of this work is to briefly review the data regard chemosurgery for RTB treatment. 
TABLE 1

Reese-Ellsworth classification for conservative treatment of retinoblastoma

\begin{tabular}{|c|l|l|}
\hline Group & Consideration & \multicolumn{1}{c|}{ Characteristics } \\
\hline I & Very favorable & $\begin{array}{l}\text { Solitary tumor, <4 disk diameters in size, at or behind the } \\
\text { equator } \\
\text { Multiple tumors, none } \\
\text { diameters in size, all at or behind the equator }\end{array}$ \\
\hline II & Favorable & $\begin{array}{l}\text { Solitary tumor, 4-10 disk diameters in size, at or behind the } \\
\text { equator } \\
\text { Multiple tumors, 4-10 disk diameters in size, behind the } \\
\text { equator }\end{array}$ \\
\hline III & Doubtful & $\begin{array}{l}\text { Any lesion anterior to the equator } \\
\text { Solitary tumors }>10 \text { disk diameters behind the equator }\end{array}$ \\
\hline IV & Unfavorable & $\begin{array}{l}\text { Multiple tumors, some }>10 \text { disk diameters } \\
\text { Any lesion extending anteriorly to the ora serrata }\end{array}$ \\
\hline V & Very unfavorable & $\begin{array}{l}\text { Massive tumors involving over half the retina } \\
\text { Vitreous seeding }\end{array}$ \\
\hline
\end{tabular}

TABLE 2

International retinoblastoma staging system

\begin{tabular}{|c|c|}
\hline Stage & Characteristics \\
\hline 0 & Patients treated conservatively \\
\hline $\mathrm{I}$ & Eye enucleated, tumor completely resected on histopathology examination \\
\hline II & $\begin{array}{l}\text { Eye enucleated, microscopic residual tumor present in the form of: } \\
\text {-Tumor invasion into extrascleral tissue } \\
\text {-Tumor invasion into cut end of optic nerve }\end{array}$ \\
\hline III & $\begin{array}{l}\text { Regional extension: } \\
\bullet \text { Overt orbital disease } \\
\bullet \text { Preauricular or cervical lymph node extension } \\
\end{array}$ \\
\hline IV & $\begin{array}{l}\text { Metastatic } \\
\text { - Hematogenous metastasis (without CNS extension) } \\
\text { - Single lesion } \\
\text {-Multiple lesions } \\
\text { Central nervous system extension (with or without any other site of regional or } \\
\text { metastatic disease) } \\
\text {-Prechiasmatic lesion } \\
\text {-Central nervous sustem mass } \\
\text { - Leptomeningeal and cerebrospinal fluid (CSF) disease }\end{array}$ \\
\hline
\end{tabular}




\section{RTB general behaviour}

RTB is the most common malignant intraocular tumor of childhood $(1,6,7)$, with a reported incidence ranging from 1 in 15,000 to 1 in 18,000 live births, independent of race and sex $(8,9)$; Kivela (10) has stated that the estimated number of patients per year with RTB worldwide was between 7202 and 8102. Approximately 250-300 children are newly diagnosed with retinoblastoma each year in the United States, and unfortunately, substantially higher rates occur in developing countries (11). Almost $80 \%$ of the cases occur before 4 years of age, while $40 \%$ of cases occur during infancy (1). It is a curable cancer if detected at a stage in which it is still contained within the retina, subretinal space or vitreous (12). The most common external features include leukokoria and strabismus (6). Approximately $80 \%-90 \%$ of RB1 gene carriers develop ocular tumors. This gene encodes the cell cycle regulatory retinoblastoma gene protein $(\mathrm{pRb})$, controls cellular differentiation during both embryogenesis and in adult tissues, regulates apoptotic cell death, maintains cell cycle arrest and preserves chromosome estability [2]. Retinoblastoma occurs in two forms: hereditary (30-40\%) and nonhereditary $(60-70 \%)$.

Despite the classic appearance of RTB, nearly $50 \%$ of patients diagnosed initially with possible retinoblastoma prove, on referral to ocular oncologists, to have simulating conditions and not retinoblastoma (13). The most common pseudoretinoblastomas include persistent hyperplastic primary vitreous, Coats disease, and ocular toxocariasis (13).

\section{Management evolution}

RTB management is complex and depends on many issues including tumor laterality, macular involvement, tumor size, vitreous or subretinal seeding, relationship of the tumor to surrounding tissues including the optic disc, choroid, iris, sclera, and orbit, general patient age and health, and the family desires (12). The treatment of RTB has evolved substantially over the last few decades $(12,14,15)$. Conservative treatment of retinoblastoma has improved in the last years. In the past, enucleation and external beam radiation therapy (EBRT) were the only treatments available for these patients (7).

Systemic chemotherapy for intraocular retinoblastoma was introduced $>50$ years ago (16). The driving force behind using systemic chemotherapy has been to avoid the radiation-related second cancers that developed in radiated retinoblastoma children (16). As had been mentioned, patients with RTB are young children and although systemic chemotherapy causes dramatic reductions in the size of the tumors (averaging $>50 \%$ decrease in volume after 3 sessions) clinicians are increasingly reporting worrisome adverse systemic findings in children treated with systemic chemotherapy (16). This therapy in the pediatric population has potential short- and long-term complications, such as neutropenia, fever, port infections, sepsis, anemia, transfusions, and associated hospitalizations have all been reported (17).

Since 1997 was previsualized newer treatment strategies directed to target cancer cell treatment, such as the delivering of a photosensitizing agent to cancer cells by a carrier molecule such as low-density lipoprotein $(6,18)$, posteriorly, a light source, e.g., laser, is then used to irradiate 
the sensitized tumor; allowing for targeted treatment with a particularly intense reaction in the tumor, sparing the normal tissue (6). All management have evolved, and currently, the most commonly employed approach for treating retinoblastoma in developed countries is chemoreduction, a strategy involving neoadjuvant systemic chemotherapy, followed by treatment with focal modalities, such as cryotherapy, laser treatment, or brachytherapy (19).

Laser photocoagulation, cryotherapy, thermotherapy, and plaque radiotherapy remain vitally important in the management of selective RTB (12). Enucleation, intravenous chemoreduction, intra-arterial chemotherapy, and EBRT are used for more advanced retinoblastoma (12). EBRT is usually reserved for last alternative treatment because of its numerous side effects and risks for late onset cancers in germline mutation children (12).

\section{Chemosurgery}

Ophthalmic artery chemosurgery (OAC) for RTB was first performed a lustrum ago by Abramson et al $(20,21)$ with the aim of preserv eyes with extensive intraocular RTB scheduled for enucleation.

The first attempt to deliver high doses to the eye, while minimizing systemic exposure was performed by Reese et al (22) more than 50 years ago, but with a different rationale; they delivered intra-arterial Triethylene Melanamine (TEM) (a nitrogen mustard derivative) via direct carotid artery puncture on the side to be treated attempting to lower the dose of therapeutic radiation used to treat RTB.

Japanese researchers have been investigated intracarotid administration of chemotherapy. Intra-arterial chemotherapy was used in 187 patients in Japan between 1988 and 2001 (23,24). Initially, they described only technical success, without efficacy or toxicity data. Some follow-up data were reported in October, 2011 (25). Ophthalmic arterial infusion of melphalan is technically feasible and can result in striking regression of tumour (16,21,26).79-81 These optimistic reports do not specify eligibility criteria, control of retinoblastoma, vision achieved, or survival rates of the eye or patient. However, in their studies, many patients received external beam radiotherapy (EBRT) and intravitreal melphalan, making it difficult to determine how effective the intraarterial injections would be if used alone (11).

Abramson et al in 2010 (16) introduced the technique of "super selective infusion" by advancing a micro-catheter into the orifice of the ophthalmic artery on the side to be treated (or both sides in the same session in cases of bilateral retinoblastoma"tandem therapy") after introduction of the catheter via the femoral artery in cases of newly diagnosed retinoblastomas. Because of their limited systemic toxicity in treating children with advanced intraocular retinoblastoma (most frequently asymptomatic Grade 3 neutropenia), they began treating less advanced retinoblastoma and in 2012 they report the success and adverse events in these patients (20); they found that ophthalmic artery chemosurgery for retinoblastoma that was ReeseEllsworth I, II and III (or International Classification B or C) was associated with high success $(100 \%$ of treatable eyes were retained) and limited toxicity with results that equal or exceed conventional therapy with less toxicity. Thus, this technique, rapidly become an accepted modality that 
saves eyes with advanced RTB that would otherwise have been enucleated.

The evidence showed that many of the eyes initially managed with systemic chemotherapy require additional treatment(s) (radiation or enucleation) to control the cancer (16), making chemosurgery an option of particular interest, because it could be performed repeatedly in young children without significant systemic or local side effects (16); furthermore, in some cases, eyes clearly can have potential useful vision (16).

Because the most newly diagnosed RTB eyes in the United States are in ReeseEllsworth group V at presentation (16), the majority of these are treated with primary enucleation; however in the Abramson (16) series, 25 of 28 were classified as ReeseEllsworth group V. They would likely have been primarily enucleated, but the intraarterial approach allowed them to save 27 of these eyes.

Abramson et al (16) 3-year experience with the use of super selective intra-arterial chemotherapy for RTB suggests that the technique is minimally toxic to the eye in previously untreated cases, has minimal systemic toxicity, can restore vision in some eyes, can be done repeatedly on an outpatient basis, and will replace the use of systemic chemotherapy, EBRT, and enucleation for the majority of retinoblastoma cases. Other reports also support those findings (27)

\section{The technique}

Chemosurgery is a method of intraarterial chemotherapy is basically a procedure in which a neuro-interventional radiologist or neurosurgeon will thread a catheter into femoral approach, reaching ophthalmic artery and releasing the medications (14). For the super selective technique described by Abramson et al (16), under general anesthesia and anticoagulation (intravenous heparin, 75I $\mathrm{U} / \mathrm{kg}$ ), is introduced into the femoral artery a 4-French arterial sheath. Microcatheters are then passed into the ophthalmic artery on the affected side using fluoroscopy and roadmapping (16). Both flow-directed catheters (such as the Magic-Balt Therapeutics, Montmorency, France) with outer diameters of 400 or 500 microns and guidewire-directed catheters (such as the Excelsior SL 10 Stryker, Freemont CA) with an outer diameter of 570 microns have been used. The chemotherapy drugs are then diluted with saline in a $30 \mathrm{cc}$ solution, injected in a pulsatile fashion over 30 minutes. At the end of the procedure the catheter is withdrawn, the femoral puncture site is compressed for hemostasis and the child discharged the same day (16).

Despite its remarkable control for retinoblastoma, some authors consider that intraarterial chemotherapy should be used with caution (14). Have been demonstrated some toxic effects of irradiation from fluoroscopy during intraarterial chemotherapy for retinoblastoma, cautioning that accumulated irradiation toxic effects following multiple sessions of intraarterial chemotherapy could be cataractogenic and possibly carcinogenic (28).

\section{Survival and outcomes}

Survival rates for intraocular RTB have improved dramatically in the past century. A disease that was 95\% lethal 100 years ago is now curable in more than $95 \%$ of cases (19); Its management relies on an experienced team, conformed by the ocular oncologists, pediatric oncologists, radiation oncologists, pediatricians, pediatric 
ophthalmologists, occasionally geneticists, and interventional neuroradiologists or neurosurgeons working together for the single goal of saving the child's life (12).

In America, the 5-year survival was 96\% between 1995 and 2004 based on Surveillance, Epidemiology, and End Results (SEER) data (29). In England, the 5-year survival between 1998 and 2002 was $97 \%$ for unilateral retinoblastoma and $100 \%$ for bilateral retinoblastoma (30).

Despite these impressive results, retinoblastoma continues to pose a serious life-threatening problem for children in developing nations, mostly due to late detection and massive tumor. The mortality rate varied tremendously by location with $3-5 \%$ mortality in Japan, Europe, and North America to $20 \%$ in Latin America/Caribbean, 39\% in Asia (without Japan), and up to $70 \%$ in Africa. He estimated that approximately 3001-3376 children die of retinoblastoma annually worldwide (10).

\section{Conclusions}

Early detection to minimize visual morbidity remains the focus of research in countries with universal access to healthcare. Late presentation with life threatening disease is a major challenge in economically underprivileged countries, and strategies must focus on raising awareness and acceptance of modern treatment methods such as chemosurgery. Fortunately the strategies for treating RTB continue evolving, some successfully, and others no. Despite advances in treatment options, clinicians continue to face challenges in improving globe salvage rates and mitigating the long-term side effects of therapy.

\author{
Correspondence \\ Dr. Luis Rafael Moscote-Salazar, Universidad \\ de Cartagena, Cartagena de Indias, Colombia, \\ mineurocirujano@aol.com
}

\section{References}

1. Bakhshi S, Bakhshi R. Genetics and management of retinoblastoma. Journal of Indian Association of Pediatric Surgeons 2007;12:109-15.

2. Ali MJ, Parsam VL, Honavar SG, Kannabiran C, Vemuganti GK, Reddy VAP. RB1 gene mutations in retinoblastoma and its clinical correlation. Saudi Journal of Ophthalmology 2010;24:119-23.

3. Fortunato P, Pillozzi S, Tamburini A, Pollazzi L, Franchi A, La Torre A, Arcangeli A. Irresponsiveness of two retinoblastoma cases to conservative therapy correlates with upregulation of hERG1 channels and of the VEGF-A pathway. BMC Cancer 2010;10:504-10.

4. Lamber EP, Beuron F, Morris EP, Svergun DI, Mittnacht S. Structural insights into the mechanism of phosphoregulation of the retinoblastoma protein. PLoS One 2013;8:e58463.

5. Viallard JF, Lacombe F, Belloc F, Pellegrin JL, Reiffers J. [Molecular mechanisms controlling the cell cycle: fundamental aspects and implications for oncology]. Cancer Radiother 2001;5:109-29.

6. Shields CL, Meadows AT, Leahey AM, Shields JA. Continuing challenges in the management of retinoblastoma with chemotherapy. Retina 2004;24:849-62.

7. Antoneli CBG, Ribeiro KCB, Steinhorst F, Novaes PERS, Chojniak MM, Malogolowkin M. Treatment of retinoblastoma patients with chemoreduction plus local therapy: experience of the AC Camargo Hospital, Brazil. J Pediatr Hematol Oncol 2006;28:342-5.

8. Bishop JO, Madson EC. Retinoblastoma. Review of the current status. Surv Ophthalmol 1975;19:342-66.

9. Abramson DH. Retinoblastoma incidence in the United States. Arch Ophthalmol 1990;108:1514.

10.Kivelä $T$. The epidemiological challenge of the most frequent eye cancer: retinoblastoma, an issue of birth and death. Br J Ophthalmol 2009;93:1129-31.

11.Meel R, Radhakrishnan V, Bakhshi S. Current therapy and recent advances in the management of retinoblastoma. Indian Journal of Medical \& Paediatric Oncology 2012;33:80-8.

12.Shields CL, Shields JA. Retinoblastoma management: advances in enucleation, intravenous chemoreduction, and intra-arterial chemotherapy. Curr Opin Ophthalmol 2010;21:203-12.

13.Shields CL, Shields JA. Recent developments in the management of retinoblastoma. J Pediatr Ophthalmol Strabismus 1999;36:8-18; quiz 35-6. 
14.Shields CL, Shields JA. Intra-arterial chemotherapy for retinoblastoma: the beginning of a long journey. Clin Experiment Ophthalmol 2010;38:638-43.

15.Schefler AC, Abramson DH. Retinoblastoma: what is new in 2007-2008. Curr Opin Ophthalmol 2008;19:526-34.

16.Abramson DH, Dunkel IJ, Brodie SE, Marr B, Gobin YP. Superselective Ophthalmic Artery Chemotherapy as Primary Treatment for Retinoblastoma (Chemosurgery). Ophthalmology 2010;117:1623-9.

17.Benz MS, Scott IU, Murray TG, Kramer D, Toledano S. Complications of systemic chemotherapy as treatment of retinoblastoma. Arch Ophthalmol 2000;118:577-8.

18.Schmidt-Erfurth U, Diddens H, Birngruber R, Hasan T. Photodynamic targeting of human retinoblastoma cells using covalent low-density lipoprotein conjugates. Br J Cancer 1997;75:54-61.

19.Martin NE, Kim JW, Abramson DH. Fibrin Sealant for Retinoblastoma: Where Are We? Journal of Ocular Pharmacology \& Therapeutics 2008;24:433-8.

20.Abramson DH, Marr BP, Brodie SE, Dunkel I, Palioura S, Gobin YP. Ophthalmic artery chemosurgery for less advanced intraocular retinoblastoma: five year review. PLoS One 2012;7:e34120.

21.Abramson DH, Dunkel IJ, Brodie SE, Kim JW, Gobin YP. A Phase I/II Study of Direct Intraarterial (Ophthalmic Artery) Chemotherapy with Melphalan for Intraocular Retinoblastoma: Initial Results. Ophthalmology 2008;115:1398-1404.e1.

22.Reese AB, Hyman GA, Tapley ND, Forrest AW. The treatment of retinoblastoma by $\mathrm{x}$-ray and triethylene melamine. AMA Arch Ophthalmol 1958;60:897-906.

23.Suzuki S, Kaneko A. Management of intraocular retinoblastoma and ocular prognosis. Int J Clin Oncol 2004;9:1-6.

24.Yamane T, Kaneko A, Mohri M. The technique of ophthalmic arterial infusion therapy for patients with intraocular retinoblastoma. Int J Clin Oncol 2004;9:6973.

25.Suzuki S, Yamane T, Mohri M, Kaneko A. Selective ophthalmic arterial injection therapy for intraocular retinoblastoma: the long-term prognosis. Ophthalmology 2011;118:2081-7.

26.Abramson DH, Dunkel IJ, Brodie SE, Marr B, Gobin YP. Superselective ophthalmic artery chemotherapy as primary treatment for retinoblastoma (chemosurgery). Ophthalmology 2010;117:1623-9.

27.Suzuki S, Yamane T, Mohri M, Kaneko A. Selective Ophthalmic Arterial Injection Therapy for Intraocular Retinoblastoma: The Long-Term Prognosis. Ophthalmology 2011;118:2081-7.

28.Vijayakrishnan R, Shields CL, Ramasubramanian A, Emrich J, Rosenwasser R, Shields JA. Irradiation toxic effects during intra-arterial chemotherapy for retinoblastoma: should we be concerned? Arch Ophthalmol 2010;128:1427-31.

29.Broaddus E, Topham A, Singh AD. Survival with retinoblastoma in the USA: 1975-2004. $\mathrm{Br} \mathrm{J}$ Ophthalmol 2009;93:24-7.

30.MacCarthy A, Birch JM, Draper GJ, Hungerford JL, Kingston JE, Kroll ME, Stiller CA, Vincent TJ, Murphy MFG. Retinoblastoma: treatment and survival in Great Britain 1963 to 2002. Br J Ophthalmol 2009;93:38-9. 